\title{
Calculating the cost of reusable materials in endourological stone surgeries
}

\author{
Haluk Soylemez ${ }^{1}$ Tahsin Batuhan Aydogan ${ }^{1}$
}

Received: 19 January 2016 / Accepted: 4 March 2016 / Published online: 17 March 2016

(C) Springer-Verlag Berlin Heidelberg 2016

Dear Sir,

I read the article by Bagcioglu et al. with great interest [1]. This is one of the first and most valuable studies in literature that compares the cost-effectiveness of micropercutaneous nephrolithotomy (microperc) and retrograde intrarenal surgery (RIRS). Working on cost-effect studies is quite difficult because they have multiple variables. Thank you to the authors for presenting this study with a clear and brief expression.

However, there seems to be a methodological mistake while calculating the costs of reusable materials per case. Disposable materials are a variable that can be taken into account on a case-by-case basis [2], but reusable materials can be used for several cases depending on their life span. For this reason, reusable materials should be calculated in a different manner. For example, the cost of a laser per case cannot be calculated by dividing the overall cost of the laser device into 309 cases because the life span of a typical laser is much more longer. Based on our experiences, a laser device can be used for more than a thousand cases. Similarly, during the calculation of the cost per case for microperc and RIRS, consideration needs to be placed on the life span of devices used in microperc and RIRS. According to our experience, we estimate that a microperc can be used for more than 63 cases and RIRS can be used for more than 48 cases. This analysis cannot give us an exact cost of the devices per each case as the fragility and life span of microperc and RIRS varies a lot among each

Tahsin Batuhan Aydogan

drbatu@hotmail.com

1 Urology Department, Faculty of Medicine, Hacettepe University Hospital, Hacettepe University, Sihhiye-Ankara, Turkey other [3]. In our clinical experiences, RIRS devices can be used up to 50-100 cases while microperc can be used in at least 150 cases. Taking everything into consideration, calculations should be made keeping in mind the average life span and annual maintenance costs of each device. Finally, we want to bring to your attention, a mistake in the total cost per case for both microperc and RIRS. These figures differ in the abstract and in the result section appearing as; $\$ 831.58, \$ 917.13 ; \$ 728.58, \$ 814.13$ respectively.

Sincerely Yours,

Haluk Soylemez

Tahsin Batuhan Aydogan

\section{Compliance with ethical standards}

Conflict of interest The authors declare that they have no conflict of interest. This article does not contain any studies with human participants or animals performed by any of the authors.

\section{References}

1. Bagcioglu M, Demir A, Sulhan H, Karadag MA, Uslu M, Tekdogan UY (2015) Comparison of flexible ureteroscopy and micropercutaneous nephrolithotomy in terms of cost-effectiveness: analysis of 111 procedures. Urolithiasis 1-6. doi:10.1007/s00240-015-0828-7

2. Shin RH, Lipkin ME, Preminger GM (2015) Disposable devices for RIRS: where do we stand in 2013? What do we need in the future? World J Urol 33(2):241-246

3. Ramon de Fata F, Hauner K, Andres G, Angulo JC, Straub M (2015) Miniperc and retrograde intrarenal surgery: when and how? Actas Urol Esp 39(7):442-450 